\title{
Hyaline-vascular variant of angiofollicular lymph node hyperplasia with systemic manifestations and response to corticosteroids
}

\author{
GP SUMMERFIELD, W TAYLOR,* AJ BELLINGHAM, HJ GOLDSMITH $\dagger$
}

From the Department of Haematology, University of Liverpool, the *Department of Histopathology, University of Liverpool, and the †Regional Department of Nephrology, Royal Liverpool Hospital, Prescot Street, Liverpool L7 8XW

SUMMARY We report two cases of angiofollicular lymph node hyperplasia of the hyaline-vascular type. The patients were atypical in having systemic complications, which are much more commonly seen in the plasma cell variant of this disorder. In each case, the diagnosis was established some years after the initial presentation. Both patients presented with unusual systemic manifestations. The exact mechanism underlying the associated features is unknown, but these cases provide some evidence that the disease is primarily a vascular proliferative or inflammatory disorder. All manifestations of the disease responded to the administration of prednisolone with rapid reduction of dosage to less than $10 \mathrm{mg}$ daily. Maintenance therapy may be required to prevent relapse.

Angiofollicular lymph node hyperplasia (ALNH) is a rarely diagnosed cause of lymphadenopathy, usually presenting at a single site. ${ }^{1}$ The condition has many synonyms, including angiomatous lymphoid hamartoma ${ }^{2}$ and giant lymph node hyperplasia of the mediastinum. ${ }^{3}$ The aetiology is unknown, but is presumed to be infectious or inflammatory, and the lymph node lesions always behave as benign tumours. ${ }^{4}$

Keller, Hochholzer and Castleman ${ }^{3}$ analysed 81 cases and divided the lesions into two types: the hyaline-vascular-in which systemic complications are not usually observed-and the plasma cell variant, which is frequently accompanied by fever, anaemia and hyperglobulinaemia. In the latter type, complete surgical resection of the tumour is followed by resolution of all the systemic manifestations. In some cases, lymphadenopathy is more generalised ${ }^{5}$ so that resection becomes difficult or impossible.

We describe two such cases in which anaemia and other associated features responded to corticosteroid therapy. Unusually, both these cases were histologically of the hyaline-vascular rather than the plasma cell type. In addition to commonly reported abnormalities, both patients had hepatomegaly with hepatic dysfunction and the second case had the nephrotic syndrome, renal failure associated with histological changes of interstitial nephritis, and congestive cardiac failure.

Until last year, only one case of the nephrotic syndrome had been reported in this disorder. ${ }^{6}$ This 18-year-old woman was cured by surgical resection of a single mesenteric lymphoid tumour showing ALNH of the plasma cell type. Recently, further patients have been reported. ${ }^{8}$ The patient described by Bartoli et al ${ }^{9}$ with multicentric ALNH of transitional histology, had hepatic and renal impairment and congestive cardiac failure but intermittent chemotherapy resulted in death from overwhelming sepsis.

In our patients there was complete resolution of symptoms and signs after continuous treatment with prednisolone. In particular, there was dramatic relief of the anaemia, which was normochromic, normocytic and associated with normal bone marrow iron stores-that is, an example of the "anaemia of chronic discrders."

\section{Case reports}

CASE 1

The patient was first seen in 1960 at the age of $39 \mathrm{yr}$. 
He had cervical lympadenopathy, which was diagnosed on biopsy as reticulum cell sarcoma and was treated with local sadiotherapy. Lymphadenopathy persisted; the biopsy was repeated in 1961 and reported as "lymphosarcomatous or chronic inflammatory."

Follow-up was continued until 1973 but he was not then seen until November 1979, at which time he complained of severe aching and oedema of the legs, associated with varicose veins. He was found to have bilateral supraclavicular and inguinal lymphadenopathy, and an inguinal node biopsy showed follicular hyperplasia with marked fibrosis. The liver was palpable at $4 \mathrm{~cm}$ and the spleen could be palpated on deep inspiration.

Investigations revealed a normochromic, normocytic anaemia ( $\mathrm{Hb} 11.2 \mathrm{~g} / \mathrm{dl})$, reticulocytes less than $1 \%$, white cell count $4.6 \times 10^{9} / 1$, platelets 274 $\times 10^{9} / 1$, ESR $36 \mathrm{~mm} / \mathrm{h}$. Plasma albumin and globulin concentrations were normal, but IgG was raised at $18.8 \mathrm{~g} / 1$ (NR 5.0-16.0 g/l). IgA and IgM were normal. Autoantibodies were negative and urea, electrolytes and liver function tests normal. Plasma fibrinogen was $4.80 \mathrm{~g} / 1$ (NR 1.5-4.0 g/l). A liver and spleen scan showed splenomegaly and poor hepatic uptake of isotope, consistent with chronic hepatitis or cirrhosis.

Over the subsequent months, the size of the lymph nodes varied but overall there was progressive enlargement. In July 1981, the patient complained of persistent tiredness, weakness and pain and swelling of the legs. There was marked

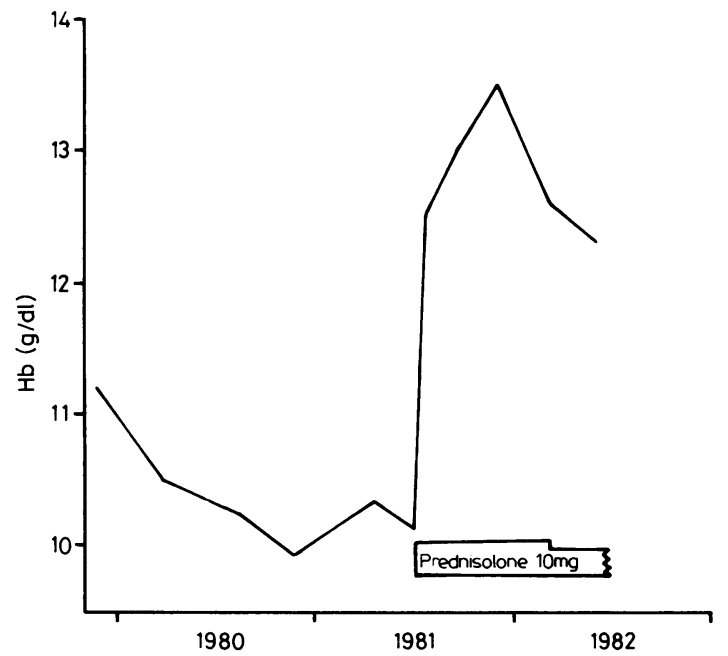

Fig. 1 Case 1. Haemoglobin concentration ( $g / d l)$ showing rapid increase into normal range after institution of low-dose prednisolone therapy.

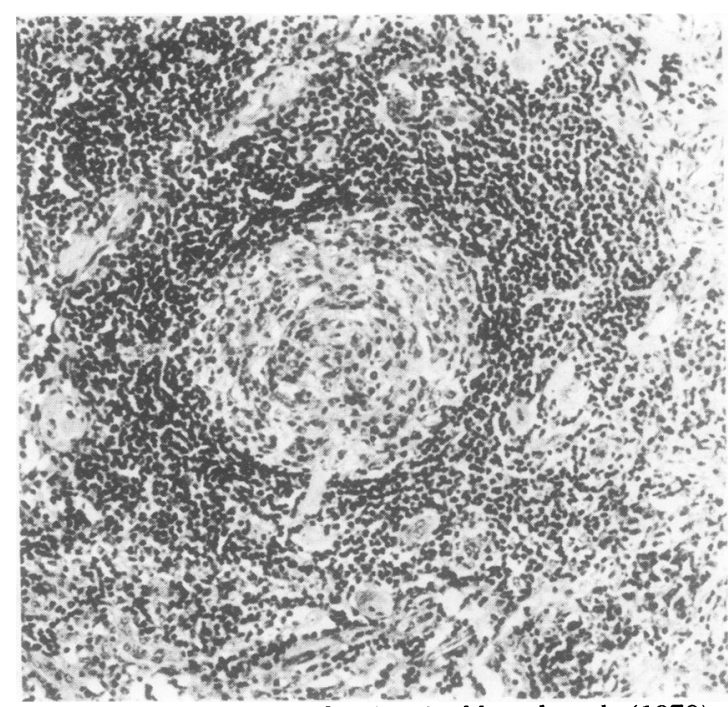

Fig. 2 Case 1. Biopsy of an inguinal lymph node (1979). A lymphocyte cuff surrounds a pale central area where the cells have a hyalinised appearance and a concentric arrangement. A small vessel penetrates the cuff of lymphocytes and enters the central area. This is probably an early lesion of hyaline-vascular ALNH. Haematoxylin and eosin $\times 150$.

enlargement of the supraclavicular, cervical and inguinal lymph nodes and the liver and spleen were both palpable at $3 \mathrm{~cm}$. The haemoglobin had fallen to $10 \cdot 1 \mathrm{~g} / \mathrm{dl}$. In view of the overall picture of an inflammatory disorder, a trial of steroids was instituted at a dose of $10 \mathrm{mg}$ prednisolone daily. There was a dramatic improvement in the lymphadenopathy and haemoglobin rose to $12.5 \mathrm{~g} / \mathrm{dl}$ in two weeks (Fig 1).

The histology of the lymph node biopsies from 1960, 1961 and 1979 was reviewed in October 1981. The 1960 specimen showed extensive proliferation of post capillary venules and only two small follicles. The 1961 biopsy, which followed radiotherapy, showed similar features but with more extensive fibrosis and less well defined follicles. Fresh sections were cut from the block from the 1979 biopsy; in these sections a few lymphoid aggregates had concentrically arranged lymphocytes and pale central cells arranged around a central ves- $\sigma$ sel as in hyaline-vascular ALNH (Fig 2).

The tissue between the lymphoid aggregates con- N sisted of hyalinised small vessels, strands of fibrous tissue, sinusoids, plasma cells and a few lympho-

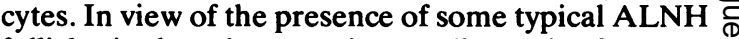
follicles in these later sections, a diagnosis of ALNH $\stackrel{?}{?}$ of the hyaline-vascular type was made.

In October 1982 the patient was very well, with 
Hyaline-vascular variant of angiofollicular lymph node hyperplasia with systemic manifestations and response to corticosteroids

no hepatosplenomegaly, minimal cervical lymphadenopathy and a normal haemoglobin concentration, taking $7.5 \mathrm{mg}$ of prednisolone daily. The pain and swelling of the legs had also improved considerably.

CASE 2

The patient was first seen in July 1977 at the age of $36 \mathrm{yr}$. He presented with abdominal pain and distension, weakness, dyspnoea on exertion and oliguria. He was found to have lymphadenopathy in the axillae, inguinal and epitrochlear regions, and some nodular cutaneous lesions on the upper abdomen. There was massive oedema of both legs up to the sacrum and lower abdomen. There were also bilateral pleural effusions and tense ascites with hepatosplenomegaly and large external haemorrhoids. The temperature was $37.5^{\circ} \mathrm{C}$.

Investigations revealed a severe normochromic, normocytic anaemia $(\mathrm{Hb} 6.9 \mathrm{~g} / \mathrm{dl})$, reticulocytes $1 \%$, direct Coombs' test negative, white cell count $5.3 \times$ $10^{9} / 1$, platelets $52 \times 10^{9} / 1\left(\mathrm{NR} 150-400 \times 10^{9} / 1\right)$, ESR $90 \mathrm{~mm} / \mathrm{h}$. Plasma albumin was $21 \mathrm{~g} / \mathrm{l}$ (NR 34 $48 \mathrm{~g} / \mathrm{l}$ ), globulin $33 \mathrm{~g} / 1$ (NR 21-31 $\mathrm{g} / \mathrm{l}$ ) and $\mathrm{IgG}$ was raised at $25 \cdot 8 \mathrm{~g} / 1$ (NR 5.0-16.0 g/l). IgA and IgM were normal. Auto-antibodies were negative with the exception of those against smooth muscle. Fibrinogen titre was $1 / 128$ (NR greater than 1/32) and FDP's greater than $40 \mu \mathrm{g} / \mathrm{ml}$ (NR $2-8 \mu \mathrm{g} / \mathrm{ml}$ ). Blood urea was $43.8 \mathrm{mmol} / \mathrm{l}$, Na $132 \mathrm{mmol} / \mathrm{l}$, K 5.9 $\mathrm{mmol} / \mathrm{l}, \mathrm{HCO}_{3} 15 \mathrm{mmol} / \mathrm{l}$ and creatinine $325 \mu \mathrm{mol} / \mathrm{l}$. Urinary protein excretion reached a maximum of $11.6 \mathrm{~g} / 24 \mathrm{~h}$. Liver function tests were normal but subsequently deteriorated transiently. The maximum value of alkaline phosphatase was 246 IU/l (NR 21-90 IU/l), alanine transaminase 39 IU/l (NR 5-28 IU/l and aspartate transaminase $61 \mathrm{IU} / 1$ (NR 5-30 IU/l). The patient rapidly became oliguric despite high-dose diuretic therapy. A diagnosis of nephrotic syndrome with acute renal failure and congestive cardiac failure was made. A Scribner shunt was inserted in the left leg in preparation for dialysis but within $24 \mathrm{~h}$ the patient developed gross pulmonary oedema and required pulmonary ventilation and daily haemodialysis with ultrafiltration.

Biopsy of an inguinal node subsequently showed marked proliferation of small vessels and a diagnosis of haemangioimmunoblastoma was suggested (Fig 3). A biopsy of an abdominal skin nodule was described as showing capillary angioma with thickened perithelial cells. Bone marrow aspirate and biopsy were hypercellular with increased megakaryocytes. Normal iron stores were demonstrated by Perls' reaction although the serum iron was low at $4.5 \mu \mathrm{mol} / 1$ (NR13-32 $\mu \mathrm{mol} / \mathrm{l})$. An

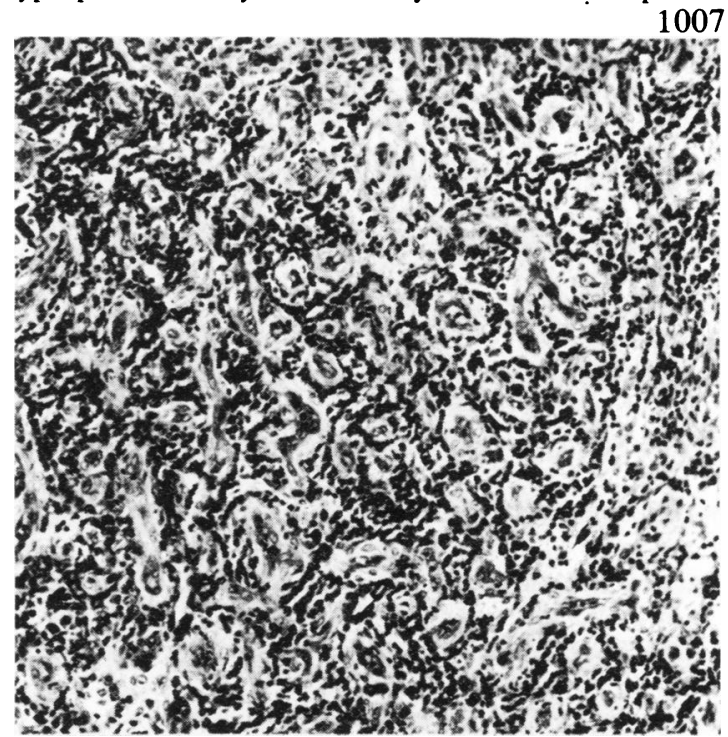

Fig. 3 Case 2. Biopsy of an inguinal lymph node (1977). There is very extensive proliferation of small but thick-walled vessels which have prominent endothelial cells. The background consists of lymphocytes and plasma cells. This appearance occupied the entire node. Haematoxylin and eosin $\times 150$.

intravenous urogram showed delayed excretion and poor concentration of contrast medium. A liver and spleen scan showed hepatomegaly and generalised reduced and patchy uptake of isotope. The spleen was enlarged and had much greater uptake than the liver. Liver biopsy revealed normal architecture with a low-grade inflammatory infiltrate in the portal tracts and liver parenchyma. The inflammatory cells were mainly neutrophils but occasional plasma cells were also present.

The patient was extubated after five days of ventilation. A renal biopsy at this stage revealed normal glomeruli, interstitial oedema and plasma cells, and tubular atrophy. A clinical diagnosis of "reticulosis" was thought probable and prednisolone $15 \mathrm{mg}$ tds was started one month after presentation. A progressive diuresis ensued and it was possible to stop haemodialysis in mid-August 1977, after six weeks of treatment. The blood urea was then $15.4 \mathrm{mmol} / \mathrm{l}$ and creatinine $102 \mu \mathrm{mol} / \mathrm{l}$. A cervical lymph node biopsy was carried out and extensive vascular proliferation was again noted, although of a nonneoplastic type. The hepatosplenomegaly, ascites and peripheral oedema persisted, but gradually resolved on a reducing dose of prednisolone, which was stopped in June 1978.

The patient was referred back to his original consultant physician in May 1979, when there were no abnormalities on examination, the full blood count, ESR and urea and electrolytes being normal. In May 
1982 he was sent again with a persistent cough and marked ankle oedema which had been partially controlled with frusemide. He became dyspnoeic on exertion, and when admitted was found to have generalised lymphadenopathy, hepatosplenomegaly, ascites and massive oedema of the legs. The clinical picture was similar to that in 1977 , and investigations confirmed a recurrence of congestive cardiac failure, renal impairment, anaemia, thrombocytopenia, raised ESR, abnormal liver function and raised IgG concentration. On this occasion, however, urinary protein excretion was only $0 \cdot 8 \mathrm{~g} / 24$ h.

Biopsy of a right cervical lymph node showed well developed ALNH of hyaline-vascular type with very marked vascular proliferation and large numbers of plasma cells between follicles (Fig. 4). The two lymph node biopsies from 1977 were reviewed. In both the inguinal and cervical lymph nodes there was prominent proliferation of postcapillary venules and large numbers of plasma cells were present in the intervening tissue. Follicles were inconspicuous but several had concentrically arranged rows of lymphocytes and a vessel arching across them (Fig.
5). In retrospect, these lymph nodes were regarded $\stackrel{\mathscr{O}}{\rightleftharpoons}$ as exhibiting early teatures of hyaline vascular $\underline{ }$ ALNH with a prounounced plasma cell component.

On this occasion, renal failure was less advanced $\stackrel{D}{\rightarrow}$ and dialysis was not required. Treatment was commenced with prednisolone $15 \mathrm{mg}$ tds and highdose frusemide. There was a satisfactory diuresis with rapid improvement of oedema and ascites.

In June 1982, he felt well on prednisolone $35 \mathrm{mg}$ od and the haemoglobin had risen from 8.0 to 11.6 $\mathrm{g} / \mathrm{dl}$, with a normal platelet count of $156 \times 10^{9} / 1$. (initially $90 \times 10^{9} / 1$ ). Plasma creatinine was normal $\overrightarrow{\vec{\omega}}$ at $86 \mu \mathrm{mol} / \mathrm{l}$, although blood urea remained raised $\stackrel{S}{S}$ at $14.7 \mathrm{mmol} / \mathrm{l}$. Abnormal liver function persisted, 8 with alkaline phosphatase 287 IU/l (NR 35-130 IU/ 1), alanine transaminase $60 \mathrm{IU} / 1$ (NR 7-45 IU/1) and 60 gamma-glutamyl transpeptidase 244 IU/l (NR 0-65 IU/1), all of which values were nevertheless considerably improved (Fig. 6). By August 1982, all biochemical variables were normal on $20 \mathrm{mg}$ prednisolone daily. A further reduction of the dose $i$ of corticosteroid is planned, but it is intended to $\mathbb{\Phi}$ maintain the patient indefinitely on $5-10 \mathrm{mg}$ of prednisolone daily.

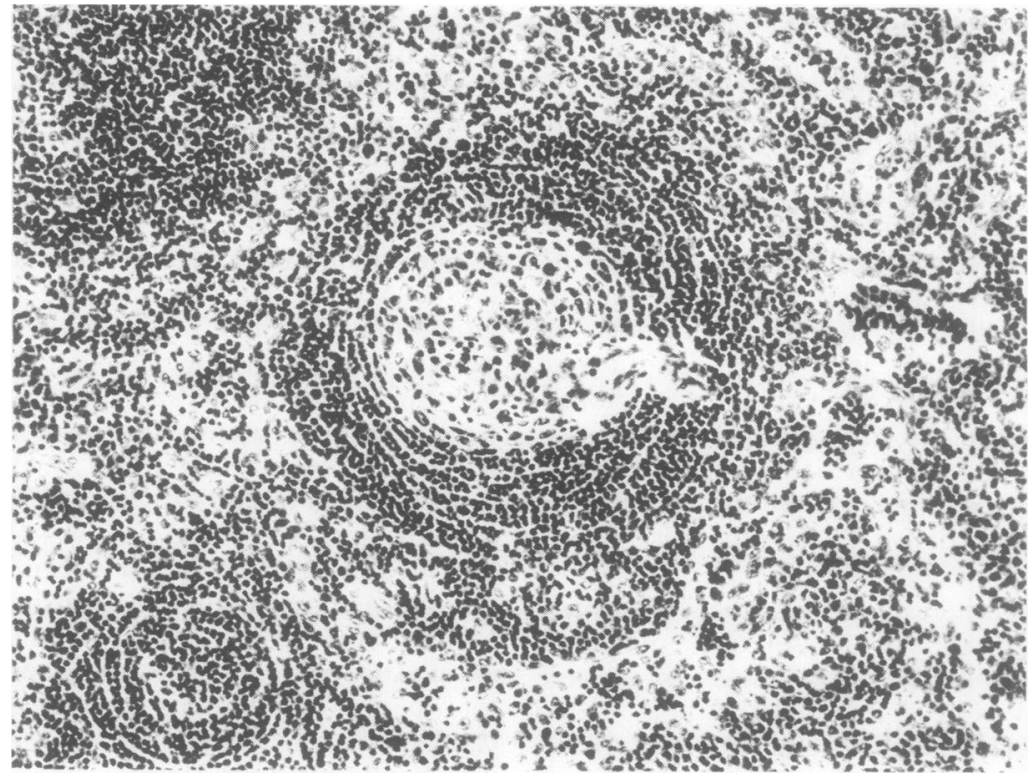

Fig. 4 Case 2. Biopsy of a cervical lymph node (1982). ALNH of hyaline-vascular type with a thick-walled vessel penetrating a cuff of concentrically arranged lymphocytes to enter the pale central area. Between the follicles there is extensive proliferation of post capillary venules and large numbers of plasma cells are present. Haematoxylin and eosin $\times 150$. 
Hyaline-vascular variant of angiofollicular lymph node hyperplasia with systemic manifestations and response to corticosteroids

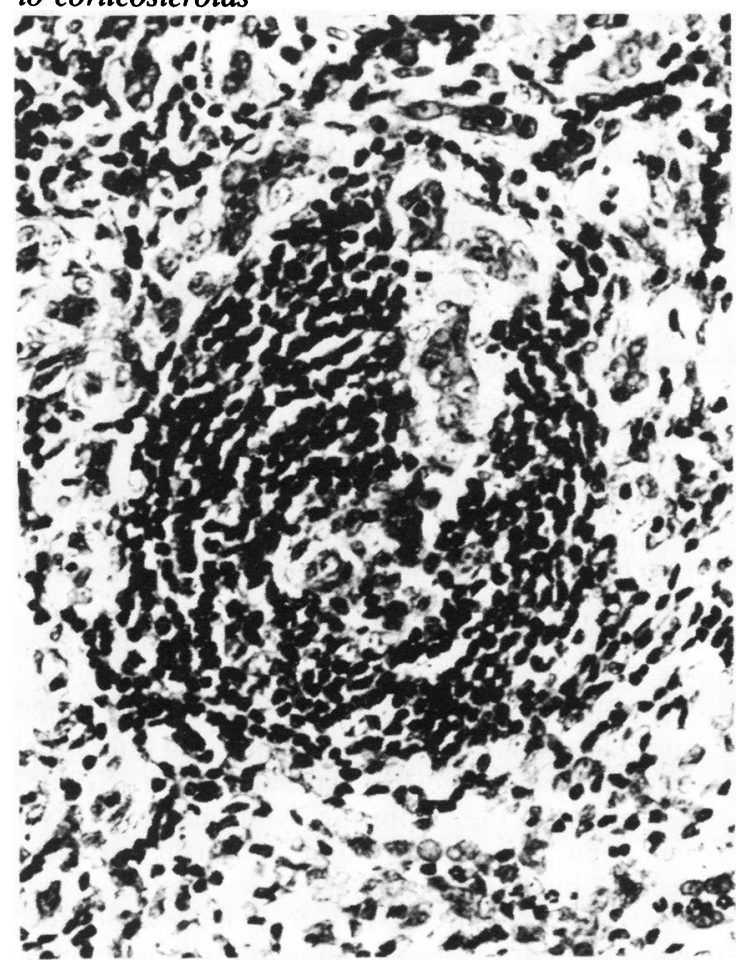

Fig. 5 Case 2. Biopsy of inguinal lymph node (1977). A thick-walled post capillary venule arches across a cuff of lymphocytes which are concentrically arranged around the vessel. This is probably an early lesion of hyaline-vascular ALNH. Haematoxylin and eosin $\times 375$.

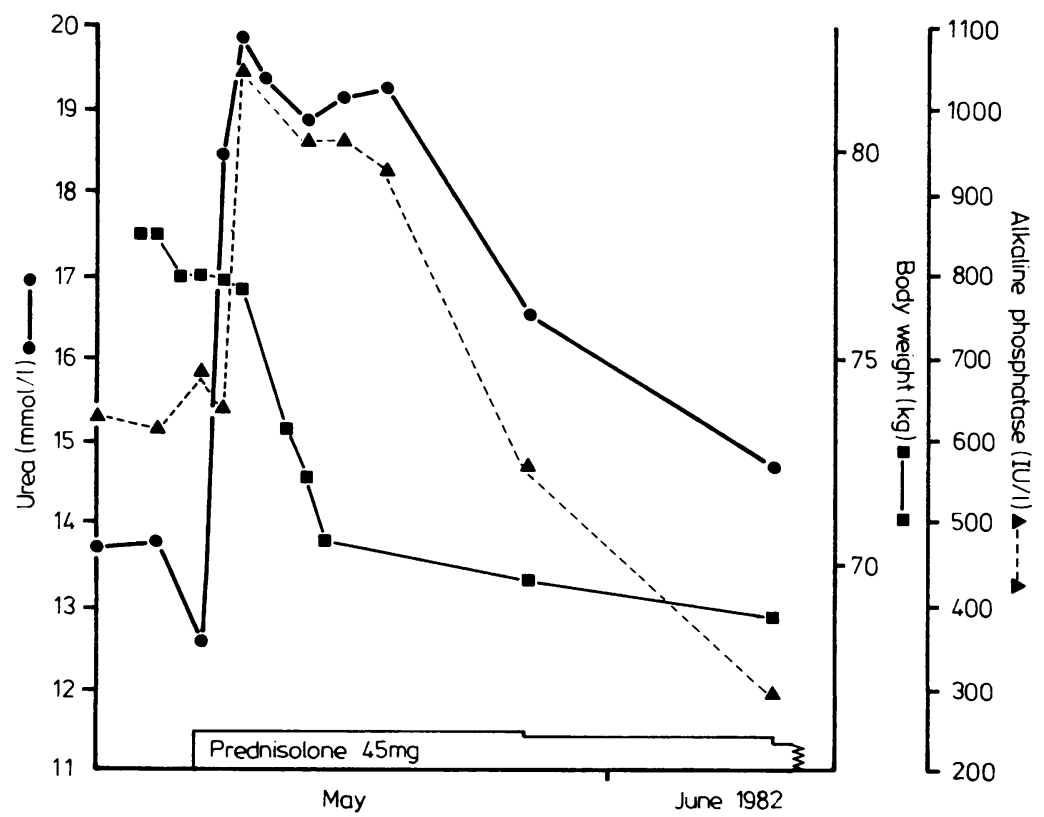

Fig. 6 Case 2. Clinical and biochemical course after presentation in relapse in May 1982. After the administration of medium-dose prednisolone, body weight fell rapidly as a diuresis occurred. Blood urea and serum alkaline phosphatase initially increased due to haemoconcentration but subsequently fell, returning to the normal range by August 1982. 


\section{Discussion}

These two cases of angiofollicular lymph node hyperplasia (ALNH) are of interest for several reasons. These include the difficulty with which the diagnosis was established, the possibility that ALNH may evolve from an earlier vascular proliferative lesion not recognisable as $\mathrm{ALNH}$, the widespread distribution of affected nodes, and finally the dramatic response to steroids which these cases exhibited.

The original diagnoses of malignancy on the 1960 and 1961 lymph node biopsies from the first case were inappropriate. The 1979 lymph node biopsy from this patient contained numerous small lymphoid aggregates, but typical arching vessels, central hyaline sclerosis and concentrically arranged lymphocytes were only identified in a few follicles when deeper sections were cut in 1981 for review.

In the second patient, the lymph node and skin lesions were interpreted in 1977 as being possibly haemangioimmunoblastoma, but a clinical diagnosis of "reticulosis" was made leading to administration of corticosteroids, which fortunately led to clinical improvement. The repeat lymph node biopsy taken in 1982 was readily recognisable as the hyalinevascular type of $A L N H$, although with very marked vascular proliferation and large numbers of interfollicular plasma cells. Review of the two 1977 lymph node biopsies then revealed features which in retrospect were recognisable as probably early ALNH lesions. The similarity of the symptoms and signs in 1977 and 1982 also suggest that the lymph node lesions of 1977 represented the same disease as those of 1982. The classical histology of hyalinevascular ALNH was not present in 1977 and the presence of considerable numbers of plasma cells seems to have been the factor relevant to the production of systemic manifestations, as in case one.

Flendrig ${ }^{5}$ discussed the possibility of a transitional type of ALNH intermediate between the hyalinevascular and plasma cell variants and these two patients probably fall into this category. Keller $e a^{3} l^{3}$ suggested that the plasma cell variant of ALNH represented an earlier, more active stage of the disease process and that the hyaline-vascular variant represented a later stage. In the present two cases the earlier lesions are not plasma cell ALNH but a hyperplastic lesion with poorly developed hyalinevascular features, vascular proliferation and considerable numbers of plasma cells. It may be that histopathologists should lower their diagnostic threshold for this rare condition and, at least, be prepared to suggest the possibility of the diagnosis before the well known fully developed histological picture is present. It must also be borne in mind that the histological appearances may vary from one part
Summerfield, Taylor, Bellingham, Goldsmith

of a lesion to another, or between a major mass and its satellite lesions. ${ }^{3}$

The occurrence of systemic manifestations has been recorded in only $3 \%$ of lesions of the hyalinevascular type. ${ }^{3}$ Flendrig ${ }^{5}$ described the systemic $\frac{\vec{O}}{\sigma}$ signs and symptoms in three patients with the $\overline{0}$ plasma cell variant. These included lym- $\overline{\frac{\sigma}{D}}$ phadenopathy in more than one region, fever, $\widetilde{D}$ splenomegaly, anaemia, leucocytosis, thrombocytosis, raised ESR, low serum albumin, raised globulin, increased fibrinogen, raised alkaline phosphatase and an excess of plasma cells in the bone $\overrightarrow{\vec{\omega}}$ marrow. Keller $e t a l^{3}$ also list sweating, fatigue, $\stackrel{\omega}{\sigma}$ hypoferraemia, hypotransferrinaemia, raised 융 alpha-2-globulin, increased bromsulphthalein reten- $\dot{i}$ tion, raised serum copper and caeruloplasmin and serum leucine-amino peptidase as systemic manifestations of this disorder.

Our two patients exhibit most of the above features, but in addition both had hepatomegaly and the second case had the nephrotic syndrome, renal failure (associated with biopsy features of interstitial nephritis) and congestive cardiac failure. Several other cases of the nephrotic syndrome in ALNH have been reported ${ }^{6-8}$ and a further patient described by Bartoli et $a l^{9}$ was very similar to our second case. A 76-year-old man had multicentrio lymphadenopathy, hepatic infiltration with lymphos cytes, plasma cells and eosinophils in the porta tracts, renal impairment (albuminuria but not neph $\%$ rotic syndrome; no renal biopsy) and mild congestive cardiac failure. Interestingly, the lymph node histology in this patient was also of the hyalinevascular type, although sheets of plasma cells were occasionally observed. This may indicate a transitional form, as discussed above. Our second patient also had thrombocytopenia rather than thrombocytosis, and this has been previously described in a case of the hyaline-vascular lesion by Krasznai and Juhasz. ${ }^{10}$ These authors suggested that the angiomatous component of the lesion acts as a "platelet-trap" leading to thrombocytopenia, as occurs in giant haemangiomata. This was supported by an increase in megakaryocytes in the bone marrow, which was also found in our patient. No fibrin was identified in the vessels in the lymph node lesions, however. Karcher et $\mathrm{al}^{7}$ have also described thrombocytopenia in this disorder.

The final point of interest in these cases is that there was a dramatic response to corticosteroid therapy. In the second patient particularly, there was parallel resolution of the cardiovascular, renal, haematological and dermatological symptoms and signs. The lymphadenopathy also responded concurrently to prednisolone suggesting that, as in localised ALNH, the systemic manifestations were secondary 
Hyaline-vascular variant of angiofollicular lymph node hyperplasia with systemic manifestations and response to corticosteroids

to the lymph node pathology. These cases shed no light, however, on the cause of this pathology, nor on the nature of the association between the lymphadenopathy and the features of a multi-system disorder. However, the initial histology in the second patient, and especially that of the skin biopsy, was suggestive of a vascular proliferation. This might explain the protean manifestations in this patient, and also the response to steroids. The more typical features of ALNH in the biopsy taken on relapse may represent the inflammatory response of lymphoid tissue to a primarily vascular lesion.

Other authors have used corticosteroids in ALNH associated with severe systemic manifestations. Couch ${ }^{11}$ reported a case of thrombotic thrombocytopenic purpura in association with localised mediastinal ALNH. The patient eventually entered a stable remission following two relapses. The treatment consisted of prednisolone combined with multiple plasmaphereses and exchange transfusions. Maintenance prednisolone was not given but antiplatelet drugs were continued in remission. Lenner and Lundgren ${ }^{12}$ treated a patient with temporal arteritis associated with localised supraclavicular ALNH. Prednisolone was used for two years with good response and no recurrence during a further two years observation after discontinuation of treatment. Prednisolone was also used in a single case of multicentric ALNH by Bartoli et al. ${ }^{9}$ As previously mentioned, this patient closely resembled our case 2 . Prednisolone was given intermittently and in combination with other agents, including cyclophosphamide, vincristine, and procarbazine. The patient responded to each course but rapidly relapsed between courses and died of fulminant sepsis.

Corticosteroids alone do not appear previously to have been used in multicentric ALNH with systemic manifestations. Both our patients responded very satisfactorily to continuous prednisolone therapy used alone, in one case starting at low dosage and in the other at high dosage with rapid reduction. The relapse of the second patient after an interval of four years shows that the underlying cause of the disorder may persist, and that low-dose prednisolone may be required to prevent recurrence. Corticosteroids offer an effective alternative to surgery in cases where complete resection of the abnormal lymphoid tissue is not practicable. Radiotherapy was successful in two patients with unresectable mesenteric tumours of the plasma cell type ${ }^{1314}$ but these were confined to one region. There has been no response to radiotherapy in patients with localised masses of the hyaline-vascular type,$^{3}$ and this form of treatment would be impractical in multifocal disease. The use of radiotherapy or combined cytotoxic chemotherapy therefore appears to be inappropriate in multifocal angiofollicular lymph node hyperplasia of the hyaline-vascular type, as in our two patients.

We should like to thank Dr MH Bennett, consultant histopathologist, Mount Vernon Hospital, Northwood, Middlesex, for reviewing the sections from both these cases, and Dr TJ Baker, consultant physician, Wrexham, for referring the second patient.

\section{References}

' Castleman B, Iverson L, Menendez VP. Localized mediastinal lymph node hyperplasia resembling thymoma. Cancer 1956;9:822-30.

${ }^{2}$ Tung KSK, McCormack LJ. Angiomatous lymphoid hamartoma. Cancer 1967;20:525-36.

${ }^{3}$ Keller AR, Hochholzer L, Castleman B. Hyaline-vascular and plasma cell types of giant lymph node hyperplasia of the mediastinum and other locations. Cancer 1972;29:670-83.

4 Anagnostou D, Harrison CV. Angiofollicular lymph node hyperplasia. J Clin Pathol 1972;25:306-11.

s Flendrig JA. Het benigne Reuzenlymfoom. Doctorate Thesis, Univerisity of Nijmegen, NV Drukkerij 'Helmond', Helmond, Holland, 1969.

${ }^{6}$ Humphreys SR, Holley KE, Smith LH, McIlrath DC. Mesenteric angiofollicular lymph node hyperplasia (lymphoid hamartoma) with nephrotic syndrome. Mayo Clin Proc 1975;50:317-21.

' Karcher DS, Pearson CE, Butler WM, Hurwitz MA, Cassell PF. Giant lymph node hyperplasia involving the thymus with associated nephrotic syndrome and myelofibrosis. Am J Clin Pathol 1982;77:100-4.

- Pilon VA, Gomez LG, Butler JJ. Systemic amyloidosis associated with a benign mesenteric lymphoid mass. Am J Clin Pathol 1982;78:112-6.

9 Bartoli E, Massarelli G, Soggia G, Tanda F. Multicentric giant lymph node hyperplasia. A hyperimmune syndrome with a rapidly progressive course. Am J Clin Pathol 1980;73:423-6.

${ }^{10} \mathrm{Krasnai} \mathrm{G}$, Juhasz I. Angiomatous lymphoid-tissue hyperplasia, $J$ Pathol 1969;97:148-51.

"Couch WD. Giant lymph node hyperplasia associated with thrombotic thrombocytopenic purpura. Am J Clin Pathol 1980;74:340-4.

${ }^{12}$ Lenner $P$, Lundgren $E^{\circ}$. Giant lymph node hyperplasia (Castlman's disease) associated with temporal arteritis. Scand J Haematol 1981;27:263-6.

${ }^{13}$ Nordström DG, Tewfik HH, Latourette HB. Plasma cell giant lymph node hyperplasia responding to radiation therapy. Am J Roentgenol 1978;130:169-71.

14 Weisenburger DD, De Gowin RL, Gibson DP, Armitage JO. Remission of giant lymph node hyperplasia with anemia after radiotherapy. Cancer 1979;44:457-62.

Requests for reprints to: Dr GP Summerfield, University Department of Haematology, Third Floor, Duncan Building, Royal Liverpool Hospital, Prescot Street, Liverpool L7 8XW, England. 